\title{
PENGARUH DIMENSI KEPEMIMPINAN INSTRUKSIKONAL KEPALA SEKOLAH TERHADAP EFIKASI DIRI GURU
}

\author{
Mukhammad Abdul Karim, Erny Roesminingsih, Soedjarwo \\ Pascasarjana Manajemen Pendidikan Universitas Negeri Surabaya \\ mukhammad.18010@mhs.unesa.ac.id; ernyroesminingsih@unesa.ac.id; \\ soedjarwo@unesa.ac.id
}

\begin{abstract}
Current research about instructional leadership and teacher selfefficacy lacked how its variable constructed. They largely treated instructional leadership and teacher self-efficacy as a single construct and ignored dimension inside. Purpose of this research is to investigate effect dimension of instructional leadership on teacher self-efficacy's dimension in Senior High School Kediri with 124 teachers as respondent gathered by cluster sampling technique. Principal Instructional Management Rating Scale (PIMRS) and Teacher Self Efficacy (TSES) are used as an instrument to measure these variables. Partial Least Squares (PLS) is used for data analysis. The result indicate that managing the instructional program and developing the school learning climate predict instructional strategies $(R 2=0.31)$, defining the school mission and developing the school learning climate predict classroom management $(R 2=0.29)$, and three dimension of instructional leadership predict student engagement $(R 2=0.30)$.
\end{abstract}

Keywords: Instructional Leadership; Teacher Self Efficacy

\section{PENDAHULUAN}

\section{A. Latar Belakang}

Efikasi diri guru dikembangkan oleh Moran, Hoy, \& Woolfolk (1998) yang diadopsi dari teori Bandura (1997) sebagai kepercayaan terhadap kapabilitasnya untuk mempengaruhi siswa dalam proses pembelajaran, semakin kuat efikasi diri guru maka semakin tahan dengan berbagai kondisi1. RAND adalah organisasi penelitian yang telah menemukan pengaruh efikasi diri guru terhadap pencapaian siswa2, kesimpulan tersebut

1 Megan Tschannen-Moran dkk., "Teacher Efficacy: Its Meaning And Measure", Review Of Educational Research, 68.2 (1998), hal. 233.

${ }^{2}$ Berawal dari penelitian Armor dkk (1976) dari organisasi Research and Development (RAND) menyimpulkan bahwa salah satu aspek dalam diri guru yang mempengaruhi pencapaian siswa adalah felt efficacious, pada tahun berikutnya Bearman dan McLaughlin (1977) menguatkan jika efikasi diri dapat mempengaruhi siswa dengan motivasi rendah. Bandura kemudian memperjelas konsep efikasi diri guru pada tahun 1997 yang merupakan pengembangan artikelnya di tahun 1977 dengan temuan adanya hubungan antara persepsi efikasi diri dengan perubahan perilaku. Bandura menegaskan bahwa efikasi diri seseorang berbeda tergantung spesifikasi aktifitasnya. Hal ini menjadi acuan bagi Moran dkk (1998) untuk mengkonsep efikasi diri yang spesifik ke guru. Lihat Armor D Oseguera dkk., Analysis Of The School Preferred Reading Program In Selected Los Angles Minority School (Santa Monica: RAND, 1976) hal. vi; Paul Bearman, Federal programs supporting educational change, vol. VII: factor affecting implementation and continuation (Santa Monica: RAND, 1977) hal. 136; Albert Bandura, "Self-Efficacy: Toward A Unifying Theory Of Behavioral Change", Psychological Review, 84.2 (1977), hal. 191-194; Albert Bandura, Self-Efficacy The Exercise Of Control (New York: Freeman 1997), hal. 43-45; Albert Bandura, 
diperkuat hasil meta analisis dari 224 artikel3. Efikasi diri guru berperan dalam membentuk pembelajaran yang efektif dan kesuksesan sekolah melalui pencapaian siswa4. Terdapat 3 dimensi efikasi diri guru, diantaranya yaitu (1) strategi pembelajaran, (2) manajemen kelas, dan (3) keterlibatan siswa5. efikasi diri tersebut bersumber pada mastery experience, vicarious experiences, verbal persuasion, dan emotional states6. Kepala sekolah mempengaruhi efikasi diri guru karena memberikan mastery experience, vicarious experiences, dan verbal persuasion melalui kepemimpinan instruksional7.

Konsep kepemimpinan instruksional dikembakan oleh Hallinger et al (1983) dari beberapa penyempurnaan penelitian terdahulu8. Kepemimpinan instruksional diartikan sebagai kepemimpinan yang berfokus terhadap pencapaian siswa dengan melakukan perencanaan, mengelola kurikulum dan pembelajaran, sebagai culture builder, serta orientasi pengembangan keprofesionalan guru dengan serangkaian dukungan dan kolaborasi seperti supervisi9. Kepemipinan ini berpengaruh terhadap pencapaian siswa secara indirect daripada kepemipinan yang lainnya10 melalui perantara visi misi, budaya sekolah, kinerja administrasi dan pengembangan profesional guru yang menciptakan

"Self-efficacy", dalam Encyclopedia Of Human Behavior Vol IV , ed. V. S. Ramachaudran (New York: Academic Press, 1994), hal. 71-81.

${ }^{3}$ Marjolein Zee, "Teacher Self-Efficacy And Its Effects On Classroom Processes, Student Academic Adjustment, And Teacher Well-Being: A Synthesis Of 40 Years Of Research", Review of Educational Research, 20.10 (2016), hal 536; Kyung Ryung Kim, "The Relationship Between Teacher Efficacy And Students' Academic Achievement: A Meta-Analysis, Social Behavior And Personality, 46.4 (2018), hal. 536

${ }^{4}$ Megan Tschannen-Moran, “The Differential Antecedents Of Self-Efficacy Beliefs Of Novice And Experienced", Teaching and Teacher Education, 23.6. (2007), hal. 943

${ }^{5}$ The Pei Ling, "The Validity And Reliability Of Teacher Efficacy Revisited In Malaysia Secondary Schools, Journal of Studies in Education, 5.1 (2015), hal. 28-29

${ }^{6}$ Moran, Teacher., hal. 228

7 Wayne K Hoy, "Teachers' sense of efficacy and the organizational health of schools", The Elementary School Journal, 93.4 (1993), hal. 365; Moran, The Differential., hal 945

${ }^{8}$ Konsep kepempinan instruksional berawal dari penelitian Weber (1971) yang berpendapat bahwa kuatnya kepemimpinan menjadi salah satu faktor penentu bagi kesuksesan sekolah, kemudian Edmonds (1979) memperjelas kuatnya kepemimpinan sebagai pemimpin dengan kemampuan administrasi untuk mengembangkan sekolah, Temuan tersebut kemudian diperdalam Bossert, Dwyer, Rowan, \& Lee (1982) yang menemukan 4 wilayah kepemimpinan kepala sekolah, yaitu (1) goals and production emphasize, (2) power and decision making, (3) organization/ coordination, dan (4) human relations serta peran kepala sekolah dalam mengkoordinasi dan mengelola program pembelajaran. Kesimpulan ini menjadi pijakan Hallinger et al (1983) dalam mengkonsep kepemimpinan instruksional. Lihat George Weber, "Inner-city Children Can Be Taught To Read: Four Successful School", Papers CBE Occasional (1971), https://eric.ed.gov, hal. 30; Ronald Edmonds, "Effective School For The Urban Poor", Educational Leadership (1979), https://semanticscholar.org, hal.22; Steven T Bossert, "The Instructional Management Role Of The Principal", Education Administration Quarterly, 18.3 (1982), hal. 37; Phillip Hallinger dkk., "Identifying the Specific Practices, Behaviors For Principals". NASSP Bulletin, 67.463 (1983), hal. 84

9 Phillip Hallinger, Assessing Instructional Leadership With The Principal Instructional Management Rating Scale (New York: Springer, 2015), hal. 7

10 Kepemipinan instruksional lebih berpengaruh daripada kepempinan transformasional, transaksional maupun strategik. Lihat Robinson dkk., "The Impact Of Leadership On Student Outcomes: An Analysis Of The Differential Effects Of Leadership Types, Educational Administration Quarterly, 44.5 (2008), hal. 668; Ryan H Shatzer dkk., "Comparing The Effects Of Instructional And Transformational Leadership On Student Achievement: Implications For Practice”, Educational Managemen Administration \& Leadership, 42.4 (2014), hal. 426 
mutual influence11, dan merupakan dasar dalam mengembangkan sekolah efektif. Kepemimpinan instruksional memiliki 3 dimensi, diantaranya yaitu (1) mendefinisikan misi sekolah, (2) mengelola kurikulum dan pembelajaran, dan (3) Menciptakan iklim sekolah positif12. Ketiga dimensi tersebut menjadi sumber efikasi karena guru diberikan kesempatan untuk mengembangkan potensinya serta lingkungan yang positif13. Konsep kepemimpinan instruksional yang dikembagkan Hallinger apabila diadopsi pendidikan Indonesia sudah sesuai dengan Permendiknas nomor 13 tahun 2007 tentang standar kepala sekolah yang diperkuat dengan Permendikbud nomor 6 tahun 2018 tentang penugasan guru sebagai kepala sekolah dan juga Permendiknas nomor 19 tahun 2007 tentang standar pengelolaan pendidikan oleh satuan pendidikan dasar dan menengah serta Permendiknas nomor 20 tahun 2007 tentang standar penilaian pendidikan.

Beberapa penelitian menyimpulkan jika kepemipinan instruksional berpengaruh terhadap efikasi diri guru14, sedangkan penelitian dari Pearce dan Zheng dkk tidak ditemukan adanya pengaruh15, namun dari beberapa penelitian tersebut ditemukan gap, yaitu beberapa penelitian hanya menjadikan efikasi diri guru maupun kepemimpinan instruksional sebagai konstruk tunggal (Hoy dan Woolfolk, 1993; Moran dan Hoy, 2007; Calik dkk., 2012; Fackler dan Malmberg, 2016; Pearce 2017; Liu dan Hallinger, 2018; Zheng dkk., 2019), sedangkan analisis yang melibatkan dimensi hanya terdapat pada salah satu dari kedua variabel saja (Duyar dkk., 2013; Bellibas dan Liu, 2017; Ma dan Marion, 2019). Hal tersebut memberikan kesempatan peneliti untuk menganalisis pengaruh ketiga dimensi kepemimpinan instruksional terhadap ketiga dimensi efikasi diri guru menggunakan analisis struktural PLS exploratory. Penelitian ini berkonstribusi

${ }^{11}$ Phillip Hallinger, "Exploring The Principals Contribution To School Effectiveness: 1980-1995", School Effectiveness and School Improvement, 9.2 (1998), hal. 187

${ }^{12}$ Hallinger dkk, Identifying., hal. 85

${ }^{13}$ Moran dkk, Teacher., hal. 220.

${ }^{14}$ Hoy, Teachers' Sense., hal. 355; Moran, The Differential., hal. 946; Segin T Calik dkk., "Examination Of Relationships Between Instructional Leadership Of School Principals And Self-Efficacy Of Teachers And Collective Teacher Efficacy", Educational Sciences: Theory \& Practice, 12.4 (2012), hal. 2501; Sina Fackler, "Teachers' Self-Efficacy In 14 OECD Countries: Teacher, Student Group, School And Leadership Effects", Teaching and Teacher Education, 56 (2016), hal 23; Shengman Liu dan Phillip Hallinger, "Principal Instructional Leadership, Teacher Self-Efficacy, And Teacher Professional Learning In China: Testing A Mediated-Effects Model", Educational Administration Quarterly, 54.4 (2018), hal 19; Ibrahim Duyar dkk., "Multilevel Analysis Of Teacher Work Attitudes The Influence Of Principal Leadership And Teacher Collaboration", International Journal of Educational Management, 27.7 (2013), hal. 713; Mehmed S Bellibas, "Multilevel Analysis Of The Relationship Between Principals' Perceived Practices Of Instructional Leadership And Teachers' Self-Efficacy Perceptions", Journal of Educational Administration, 55.1 (2017), hal. 61; Xiaorong Ma dan Russ Marion, "Exploring How Instructional Leadership Affects Teacher Efficacy: A Multilevel Analysis", Educational Management Administration \& Leadership, 21 (2019), hal. 13

${ }_{15}$ Michelle E Pierce, "The effects of instructional leadership on teacher efficacy", Disertasi, semanticscholar.org , (Kennesaw: Kennesaw State University, 2017), hal. 54; Yin X Zheng dkk., "Exploring The Relationships Among Instructional Leadership, Professional Learning Communities And Teacher Self-Efficacy In China”, Educational Management Administration \& Leadership, 47.6 (2019), hal. 11 
untuk memperluas kajian yang ada dengan melibatkan dimensi dalam mengkonstruk kedua variabel, sehingga dapat memberikan gambaran yang lebih spesifik.

\section{B. Rumusan Masalah}

Rumusan masalah penelitian ini adalah sebagai berikut:

1. Bagaimana pengaruh mendefinisikan misi sekolah, mengelola kurikulum pembelajaran, dan menciptakan iklim sekolah positif terhadap efikasi diri guru dalam hal strategi pembelajaran di SMAN Kota Kediri?

2. Bagaimana pengaruh mendefinisikan misi sekolah, mengelola kurikulum pembelajaran, dan menciptakan iklim sekolah positif terhadap efikasi diri guru dalam hal manajemen kelas di SMAN Kota Kediri?

3. Bagaimana pengaruh mendefinisikan misi sekolah, mengelola kurikulum pembelajaran, dan menciptakan iklim sekolah positif terhadap efikasi diri guru dalam hal keterlibatan siswa di SMAN Kota Kediri?

\section{KAJIAN TEORI}

\section{A. Kepemimpinan Instruksional}

Kepemimpinan instruksional adalah kepemipinan yang berfokus terhadap pencapaian siswa dengan melakukan perencanaan sekolah, mengelola kurikulum dan pembelajaran, culture builder yang berorientasi pada pengembangan keprofesionalan guru melalui support dan kolaborasi seperti supervisi ${ }^{16}$. Kepemipinan instruksional merupakan dasar dalam mengembangkan sekolah ${ }^{17}$. Kepemimpinan instruksional memiliki 3 dimensi, yaitu (1) mendefinisikan misi sekolah, (2) mengelola kurikulum dan pembelajaran, dan (3) Menciptakan iklim sekolah positif. Mendefinisikan tujuan sekolah mencakup perencanaan dan komunikasi tujuan sekolah yang berorientasi pada siswa, mengelola kurikulum dan pembelajaran berupa mengkoordinasi kurikulum, supervisi dan evaluasi, dan memonitor perkembangan siswa, menciptakan iklim sekolah positif berupa pengembangan profesional guru, menjaga visibilitas, melindungi waktu pembelajaran, memberikan dukungan pembelajaran dan kepada guru ${ }^{18}$. Ketiga dimensi tersebut dapat menjadi sumber efikasi diri karena guru diberikan kesempatan untuk mengembangkan potensinya serta lingkungan yang positif ${ }^{19}$.

\section{B. Efikasi Diri Guru}

kepercayaan terhadap kapabilitasnya untuk mempengaruhi siswa dalam proses pembelajaran, semakin kuat efikasi diri guru maka semakin tahan dengan berbagai kondisi. Efikasi diri guru memiliki 3 dimensi, yaitu (1) strategi pembelajaran, (2)

\footnotetext{
${ }^{16}$ Hallinger, Assesing., hal. 7

${ }^{17}$ Phillp Hallinger, "The Evolving Role Of American Principals: From Managerial To Instructional To Transformational Leaders”, Journal of Educational Administration, 30.3 (1992), hal. 37

${ }^{18}$ Hallinger, Identifying., hal. 85; Hallinger, Assesing., hal. 25

${ }^{19}$ Moran dkk, Teacher., hal. 220.
} 
manajemen kelas, dan (3) keterlibatan siswa ${ }^{20}$. Strategi pembelajaran mengacu pada kepercayaan dalam melaksanakan pembelajaran seperti implementasi strategi dan penilaian yang berfariasi dengan berorientasi pada perkembangan siswa dan mencoba berbagai pendekatan agar menciptakan proses pembelajaran yang efektif ${ }^{21}$. Guru dengan efikasi tinggi cenderung lebih kreatif dan inovatif dalam strategi pembelajaran ${ }^{22}$. Manajemen kelas mengarah pada kepercayaan dalam menciptakan kelas yang kondusif, mampu menghadapi masalah, serta melakukan berbagai strategi agar siswa mengikuti peraturan kelas. Dimensi ini merupakan aspek yang penting dalam menciptakan kondusifitas dalam pembelajaran ${ }^{23}$. Keterlibatan siswa mengarah pada kepercayaan dalam membangun hubungan siswa dengan menciptakan emosi positif seperti antusias, optimis, dan ketertarikan pada pembelajaran, mengembangkan potensinya, serta memberikan dukungan kepada siswa yang memiliki motivasi rendah ${ }^{24}$. Dimensi ini menjadi faktor krusial karena mampu mempengaruhi pencapaian siswa ${ }^{25}$. Sumber efikasi diri guru yaitu mastery experience, vicarious experiences, verbal persuasion, dan emotional states. Kepala sekolah mempengaruhi efikasi diri guru karena menumbuhkan mastery experience dan vicarious experiences melalui kegiatan pengembangan keprofesionalan dan support kepada guru, memberikan verbal persuation berupa kolaborasi langsung ketika melakukan supervisi serta perannya dalam mengambil keputusan, mengelola administrasi, memberikan dukungan dan reward kepala semua elemen sekolah ${ }^{26}$.

\section{Pengaruh Kepemimpinan Instruksional Terhadap Efikasi Diri Guru}

Kepemimpinan instruksional berpengaruh terhadap efikasi diri guru, karena kepala sekolah memberikan gambaran visi misi sekolah, mengklarifikasi standar guru dan siswa, pengembangan kompetensi guru, dan pembinaan dalam pembelajaran ${ }^{27}$. Dimensi kepemipinan instruksional yang mempengaruhi efikasi diri guru adalah menciptakan iklim sekolah positif, pemberian support dengan menciptakan budaya sekolah yang

${ }^{20}$ Megan Tschannen-Moran dkk., "Teacher Efficacy: Its Meaning And Measure", Review Of Educational Research, 68.2 (1998), hal. 233.

${ }^{21}$ Teh Pei Ling dkk., “. (2015). "The Validity And Reliability Of Teacher Efficacy Revisited In Malaysia Secondary Schools”, Journal of Studies in Education, 5.1 (2015), hal. 29

${ }^{22}$ Ghaith dan Yaghi, "Relationships Among Experience, Teacher Efficacy, And Attitudes Toward The Implementation Of Instructional Innovation", Teaching and Teacher Education, 13.4 (1997), hal. 456

${ }^{23}$ Ling dkk, The Validity., hal. 29

${ }^{24}$ Moran dkk, Teacher., hal. 223; Charles S Jaggernauth, “An Investigation Of The Influence Of Teacher Variables On Pre-Training Efficacy Beliefs. Caribbean Teaching Scholar. 5.1 (2015), hal. 7

${ }^{25}$ Hyungsim Jang dkk., "Engaging Students In Learning Activities: It Is Not Autonomy Support Or Structure But Autonomy Support And Structure. American Psychological Association, 102.3 (2010), hal.588

${ }^{26}$ Moran, Teacher., hal. 228; Moran, The Differential., hal. 945; Fackler, Teacher., hal. 7

${ }^{27}$ Hoy, Teacher., hal. 355; Moran, The Differential., hal. 946; Calik dkk, Examination., hal. 2501; Fackler, Teachers., hal. 23; Hallinger, Principal., hal. 19. 
berorientasi pada pengembangan kualitas sekolah akan menambah efikasi diri guru ${ }^{28}$. Perilaku dari dimensi kepemipinan instruksional yang berpengaruh terhadap efikasi diri guru adalah merencakan dan mengkomunikasikan misi sekolah, memberikan bimbingan, feedback, support, kolaborasi supervisi pembelajaran seperti observasi kelas, memonitor perkembangan siswa, dan memberikan saran terkait pembelajaran, dan kelima perilaku dalam dimensi menciptakan iklim sekolah positif ${ }^{29}$. Perilaku tersebut membuat guru mengenali tujuan dan usaha spesifik untuk meraihnya dan meningkatkan efikasi dirinya karena mendapatkan dukungan dan lingkungan positif ${ }^{30}$. Ditinjau dari dimensi efikasi diri guru, kepemipinan instruksional berpengaruh terhadap strategi pembelajaran, manajemen kelas, \& keterlibatan siswa ${ }^{31}$. Kejelasan perencanaan sekolah dan komunikasi berpengaruh dalam membentuk strategi pembelajaran dan manajemen kelas ${ }^{32}$ Bimbingan kepala sekolah dalam mengembangkan potensi guru dan bertanggung jawab atas capaian siswa berpengaruh kepada implementasi strategi pembelajaran, manajemen kelas, dan keterlibatan siswa ${ }^{33}$.

\section{METODE PENELITIAN}

Metode penelitian ini menggunakan cross-sectional survey. Kota Kediri memiliki 8 SMAN di 3 kecamatan berbeda (4 SMAN di Kecamatan Mojoroto, 3 SMAN di Kecamatan Kota, dan 1 SMAN di Kecamatan Pesantren). Peneliti mengambil 2 SMAN di Kecamatan Mojoroto, 2 SMAN di Kecamatan Kota, dan 1 SMAN di Kecamatan Pesantren untuk mendapatkan data yang representatif. Rata-rata sampel setiap sekolah ditentukan dengan memperhatikan design effect (deff), dimana $\rho$ adalah Interclass Correlation Coeficient $(\mathrm{ICC})$ dan $\mathrm{c}=$ rata-rata sampel ${ }^{34}$. Besarnya deff untuk desain yang baik terletak diantara 1-3 dengan rekomendasi antara 0,10 sampai 0,25 untuk efek guru dan sekolah. Penelitian ini menggunakan ICC $=0,10$, semakin kecil nilai ICC akan

${ }^{28}$ Theodore Coladarci, “Teachers' Sense Of Efficacy And Commitment To Teaching”, The Journal of Experimental Education, 60.4 (1992), hal. 323; Bandura, Self-Efficacy., hal. 244; Marion, Exploring., hal. 13

29 Tamella Horton, "The relationship between teachers' sense of efficacy and perceptions of principal instructional leadership behaviors in high poverty schools", disertasi, https://rc.library.uta.edu/ (Arlington: The University of Texas, 2013), hal. 93: Duyar dkk, Multilevel., hal. 713; Bandura, SelfEfficacy., hal. 101; Marion, Exploring., hal. 14.

${ }^{30}$ Robinson dkk., The Impact., hal. 659; Hoy, Teachers., hal. 365; Bandura, Self-Efficacy., hal. 244

${ }^{31}$ Horton, The Relationship., hal. 94; Bellibas, Multilevel., hal. 61

32 Kristine A Hipp, Exploring Relationships Between Principals' Leadership Behaviors And Teachers' Sense Of Efficacy, Paper (New York: Ball State University, 1996), hal.17; J Walker, "The Impact Of Principal Leadership Behaviors On The Efficacy Of New And Experienced Middle School Teachers", NASSP Bulletin, 95.1 (2011), hal 46; Horton, The Relationship., hal. 94

${ }^{33}$ Bellibas, Multilevel., hal. 49

${ }^{34}$ Leslie Kish, Statistical design for research (Hoboken: John Wiley, 2004), hal. 36; M Fahimi, “Cluster sample”, dalam Encyclopedia Of Survey Research Methods, ed. P. J. Lavrakaspp (Thousand Oaks, CA: Sage, 2008), hal. 98. 
semakin baik reliabilitas estimasi sampel ${ }^{35}$. Rata-rata sampel sebanyak 30, didapat dari total sampel berdasarkan rumus Isaac and Michael $^{36}$ yaitu 152 guru dibagi 5 sekolah, maka maksimum sampel per sekolah adalah 30 yang diberikan secara random.

$\operatorname{deff}=\rho(c-1), 1<0.10(30-1)<3$

Angket telah terisi sebanyak 124 dengan response rate sebesar $81,58 \%$. Total responden sebesar 124 telah mencukupi batas minimum sampel dengan population effect size (ES) 0,80 dan level signifikansi 0,05 dalam melakukan tes multiple partial correlation sesuai dengan rekomendasi Cohen ${ }^{37}$. Gambaran demografis disajikan dalam Tabel 1. Instrumen untuk mengukur kepemimpinan instruksional menggunakan Principal Instructional Management Rating Scale (PIMRS) short form sebanyak 22 item untuk mengukur 3 dimensi kepemimpinan instruksional dengan 5 level skala likert, yaitu mendefinisikan misi sekolah (MMS), mengelola kurikulum dan pembelajaran (MKP), dan menciptakan iklim sekolah positif (MIS) sedangkan Efikasi diri guru diukur dengan Teacher Self Efficacy Scale (TSES) short form sebanyak 12 item untuk mengukur 3 dimensi efikasi diri guru dengan 5 level skala likert, diantaranya yaitu strategi pembelajaran (SP) manajemen kelas (MK), dan keterlibatan siswa (KS). Analisis data menggunakan Partial Least Squares (PLS) dengan software SmartPLS 3.0 untuk mengetahui hubungan antar variabel. Kelebihan penggunaan PLS adalah mampu menganalisa model struktural yang kompleks dengan sampel yang relatif kecil dan tidak ada asumsi distribusi data tertentu. Proses analisis PLS terbagi menjadi dua tahap, yaitu evaluasi outer model kemudian inner model, prosedur bootstrapping dengan 5,000 sampel digunakan untuk menentukan signifikansi outer loading dalam outer model dan hubungan antar variabel laten dalam inner model secara berturutan ${ }^{38}$.

Tabel 1 Gambaran Demografis

\begin{tabular}{lcc}
\hline \multicolumn{1}{c}{ Demografis } & Total & Persentase \\
\hline Jenis Kelamin & & \\
$\quad$ Pria & 59 & 47,6 \\
$\quad$ Wanita & 65 & 52,4 \\
Ijazah & & \\
S1 & 91 & 73,4 \\
S2 & 33 & 26,6 \\
Masa Kerja & & \\
0-5 tahun & 29 & 23,4 \\
6-14 tahun & 32 & 25,8 \\
Diatas 15 tahun & 63 & 50,8 \\
\hline
\end{tabular}

${ }^{35}$ Besty D McCoach, "Dealing With Dependence: Understanding The Effects Of Clustered Data", Gifted Child Quarterly, 54.2 (2010), hal. 155; G Shackman, Design effect (Albani: American Statistical Association), hal 1

${ }^{36}$ Ali Anwar, Statistika untuk penelitian pendidikan (Kediri: IAIT Press, 2009), hal. 27

${ }^{37}$ Jacob Cohen, “A Power Primer”, Psychological Bulletin, 112.1 (1992), hal. 158

${ }^{38}$ Joseph F Hair, A Primer On Partial Least Squares Structural Equation Modeling (PLS-SEM). (Thousand Oaks: SAGE, 2017), hal. 31; Wayne W Chin, "How To Write Up And Report PLS Analys", dalam Handbook Of Partial Least Squares, eds. V. E. Vinzi (Berlin: Springer, 2010), hal. 659 


\section{HASIL PENELITIAN DAN PEMBAHASAN}

\section{A. Common Method Bias}

Pengukuran kepemimpinan instruksional maupun efikasi diri guru dengan self assesment, diambil dari sumber yang sama dan dalam satu waktu rentan terjadi bias atau Common Method Variance (CMV). CMV adalah salah satu sumber error pengukuran dan mengacu pada korelasi palsu yang menyebabkan kesalahan dalam pengambilan kesimpulan $^{39}$. Untuk meminimalisir CMV penelitian ini menggunakan Protecting respondent anonymity sebagai procedural remedies, sedangkan untuk mendeteksi adanya CMV menggunakan Harman's single-factor test dan Variance Inflation Factor (VIF) sebagai statictical remedies. Hasil Harman's single factor dengan memasukkan semua item konstruk kedalam analisis faktor menggunakan SPSS adalah 30,95\%, maka tidak terjadi CMV karena $<50 \%$, sedangkan nilai VIF dari output SmartPLS menununjukkan tidak adanya CMV, karena nilai VIF pada inner model (Tabel 2) $<3.3^{40}$

Tabel 2. Nilai Inner VIF

\begin{tabular}{cccc}
\hline Konstruk & SP & MK & KS \\
\hline MMS & 1,56 & 1,56 & 1,56 \\
MKP & 2,06 & 2,06 & 2,06 \\
MIS & 1,71 & 1,71 & 1,71 \\
\hline
\end{tabular}

\section{B. Evaluasi Outer Model}

Pengukuran outer model dengan melihat nilai indicator reliability, composite reliability convergent validity, dan discriminant validity yang merepresentasikan validitas dan reliabilitas outer model. Indicator reliability didasarkan pada nilai loading item $>0.7$ (Hair et al., 2017). Item X1.4, X2.2, X2.3, X2.6, X3.6, X3.7, X3.8, X3.9, X3.10, dan Y1.3 dihapus karena nilai loadingnya $<0.7$, dan 24 item yang tersisa memiliki nilai loading $>0,7$ (Lampiran 1). Batas nilai Composite Reliability (CR) adalah 0,8, dengan nilai Alpha Chrobach $(\mathrm{AC})>0.7$ dan Convergent validity mengacu pada nilai Average Variance Extracted (AVE) dengan batas 0,50, sedangkan discriminant validity dapat diukur dengan 3 cara, yaitu (1) dengan melihat nilai AVE yang diakar pangkat dua harus lebih tinggi daripada korelasi antar konstruk, (2) cross-loading, yaitu nilai loading suatu konstruk harus lebih besar daripada loading konstruk lainnya, dan (3) Heterotrait-Monotrait ratio of correlation (HTMT) yang mengacu pada rasio korelasi variabel terhadap korelasi antar

${ }^{39}$ George dan Pandev, "We Know The Yin But Where Is The Yang? Toward A Balanced Approach On Common Source Bias In Public Administration Scholarship", Review of Public Personnel Administration, 37.2 (2017), hal. 246; Philip M Podsakoff dkk., "Common Method Biases In Behavioral Research: A Critical Review Of The Literature And Recommended Remedies”, Journal of Applied Psychology, 88.5 (2003), hal. 887

${ }^{40}$ Podsakov dkk, Common., hal. 888 
variabel dengan nilai $<0.85^{41}$. Tabel 3 menunjukkan jika nilai $\mathrm{CR}>0,8$, nilai $\mathrm{AC}>0,7$, dan nilai AVE $>0,5$. Discriminant validity berupa nilai AVE yang diakar pangkat dua (Tabel 4) lebih tinggi daripada korelasi antar konstruk, nilai HTMT (Tabel 5), dan nilai cross loading (Lampiran 1) telah memenuhi kriteria. Berdasarkan hasil data tersebut maka dapat dinyatakan bahwa evaluasi outer model sudah valid dan reliabel, karena memenuhi persyaratan yang telah disebutkan.

Tabel 3. Nilai CR, AC, dan AVE

\begin{tabular}{cccc}
\hline Konstruk & CR & AC & AVE \\
\hline MMS & 0,89 & 0,84 & 0,67 \\
MKP & 0,85 & 0,78 & 0,59 \\
MIS & 0,86 & 0,81 & 0,56 \\
SP & 0,88 & 0,80 & 0,71 \\
MK & 0,88 & 0,82 & 0,65 \\
KS & 0,85 & 0,77 & 0,59 \\
\hline
\end{tabular}

Tabel 4. Nilai AVE akar pangkat dua (Fornell-Lacker Criterion)

\begin{tabular}{ccccccc}
\hline & MK & SP & MKP & MIS & MMS & KS \\
\hline MK & $\mathbf{0 , 8 1}$ & & & & & \\
SP & 0,65 & $\mathbf{0 , 8 4}$ & & & & \\
MKP & 0,45 & 0,52 & $\mathbf{0 , 7 7}$ & & & \\
MIS & 0,46 & 0,48 & 0,64 & $\mathbf{0 , 7 5}$ & & \\
MMS & 0,45 & 0,33 & 0,59 & 0,46 & $\mathbf{0 , 8 2}$ & \\
KS & 0,67 & 0,67 & 0,45 & 0,53 & 0,31 & $\mathbf{0 , 7 7}$ \\
\hline
\end{tabular}

Tabel 5. Nilai HTMT

\begin{tabular}{ccccccc}
\hline & KS & MIS & MK & MMS & MKP & SP \\
\hline KS & & & & & & \\
MIS & 0,63 & & & & & \\
MK & 0,81 & 0,54 & & & & \\
MMS & 0,35 & 0,51 & 0,52 & & & \\
MKP & 0,55 & 0,77 & 0,53 & 0,68 & & \\
SP & 0,85 & 0,56 & 0,79 & 0,37 & 0,63 & \\
\hline
\end{tabular}

\section{Evaluasi Inner Model}

Pengukuran inner model mengacu pada nilai $\mathrm{R}^{2}$ sesuai pendapat dengan nilai 0,67 , 0,33, dan 0,19 yang merepresentasikan pengaruh kuat, sedang, dan lemah. Ketiga dimensi kepemipinan instruksional berkonstribusi sebesar 29\% terhadap manajemen kelas, $31 \%$ terhadap strategi pembelejaran, dan 30\% terhadap keterlibatan siswa yang menjadi dimensi efikasi diri guru. Ketiga nilai $\mathrm{R}^{2}$ tersebut termasuk dalam kategori lemah. Hal ini

${ }^{41}$ Claes Fornell Dafid F Larcker, " Evaluating Structural Equation Models With Unobservable Variables And Measurement Error" Journal of Marketing Research, 18 (1981), hal. 41; Jorg Henseler dkk., "A New Criterion For Assessing Discriminant Validity In Variance-Based Structural Equation Modeling", Journal of the Academy of Marketing Science, 43 (2015), hal. 120; Chin, How To., hal. 669; Hair dkk, A Primer., hal. 104-221 
diikuti dengan effect size tiap variabel (Tabel 6). Kriteria effect size menurut Cohen yaitu nilai 0,35, 0,15, dan 0,02 yang merepresentasikan pengaruh kuat, sedang, dan lemah. Berdasarkan data pada Tabel 6 dapat disimpulkan bahwa effect size dari semua variabel yang dianalisis tergolong lemah ${ }^{42}$.

Uji hipotesis dilakukan dengan bootstrapping 5000 sampel dengan batas nilai $t>$ 1,96 dengan level signifikansi 0,05 untuk menerima hipotesis alternatif ${ }^{43}$. Gambar 1 dan Tabel 6 menunjukkan dimensi Kepemipinan Instruksional (KI) yang berpengaruh signifikan terhadap manajemen kelas adalah mendefinisikan tujuan sekolah $(\beta=$ $0,26, t>1,96)$ dan menciptakan iklim sekolah positif $(\beta=0,26, t>1,96)$, dimensi KI yang berpengaruh terhadap strategi pembelajaran adalah mengelola kurikulum pembelajaran $(\beta=0,37, t>1,96)$ dan menciptakan iklim sekolah positif $(\beta=$ $0,241, t>1,96)$, sedangkan deminsi KI yang berpengaruh terhadap keterlibatan siswa adalah mendefinisikan tujuan sekolah $(\beta=0,02, t>1,96)$, mengelola kurikulum pembelajaran $(\beta=0,17, t>1,96)$, dan menciptakan iklim sekolah positif $(\beta=$ $0,41, t>1,96)$. Berikut adalah ringkasan dari pengujian hipotesis yang dilakukan.

Tabel 6. Uji Hipotesis

\begin{tabular}{|c|c|c|c|c|c|c|}
\hline Hipotesis & $\mathrm{R}^{2}$ & Effect Size & Beta & Nilai $t$ & Nilai $p$ & Keputusan \\
\hline $\mathrm{KI} \rightarrow \mathrm{SP}$ & 0,31 & & & & & \\
\hline $\mathrm{MMS} \rightarrow \mathrm{SP}$ & & 0 & $-0,01$ & 0,02 & 0,98 & Ditolak \\
\hline $\mathrm{MKP} \rightarrow \mathrm{SP}$ & & 0,10 & 0,37 & 3,84 & 0,00 & Diterima \\
\hline $\mathrm{MIS} \rightarrow \mathrm{SP}$ & & 0,05 & 0,24 & 2,79 & 0,01 & Diterima \\
\hline $\mathrm{KI} \rightarrow \mathrm{MK}$ & 0,29 & & & & & \\
\hline $\begin{array}{c}\mathrm{MMS} \rightarrow \\
\mathrm{MK}\end{array}$ & & 0,06 & 0,26 & 2,45 & 0,01 & Diterima \\
\hline $\mathrm{MKP} \rightarrow \mathrm{MK}$ & & 0,01 & 0,13 & 1,16 & 0,25 & Ditolak \\
\hline $\mathrm{MIS} \rightarrow \mathrm{MK}$ & & 0,06 & 0,26 & 2,42 & 0,02 & Diterima \\
\hline $\mathrm{KI} \rightarrow \mathrm{KS}$ & 0,30 & & & & & \\
\hline $\mathrm{MMS} \rightarrow \mathrm{KS}$ & & 0 & 0,02 & 0,17 & 0,87 & Ditolak \\
\hline $\mathrm{MKP} \rightarrow \mathrm{KS}$ & & 0,02 & 0,17 & 1,31 & 0,19 & Ditolak \\
\hline $\mathrm{MIS} \rightarrow \mathrm{KS}$ & & 0,14 & 0,41 & 2,79 & 0,01 & Diterima \\
\hline
\end{tabular}

${ }^{42}$ Chin, How To Write., hal. 675; Cohen, A Power., hal. 157

${ }^{43}$ Hair dkk, A Primer., hal. 149 


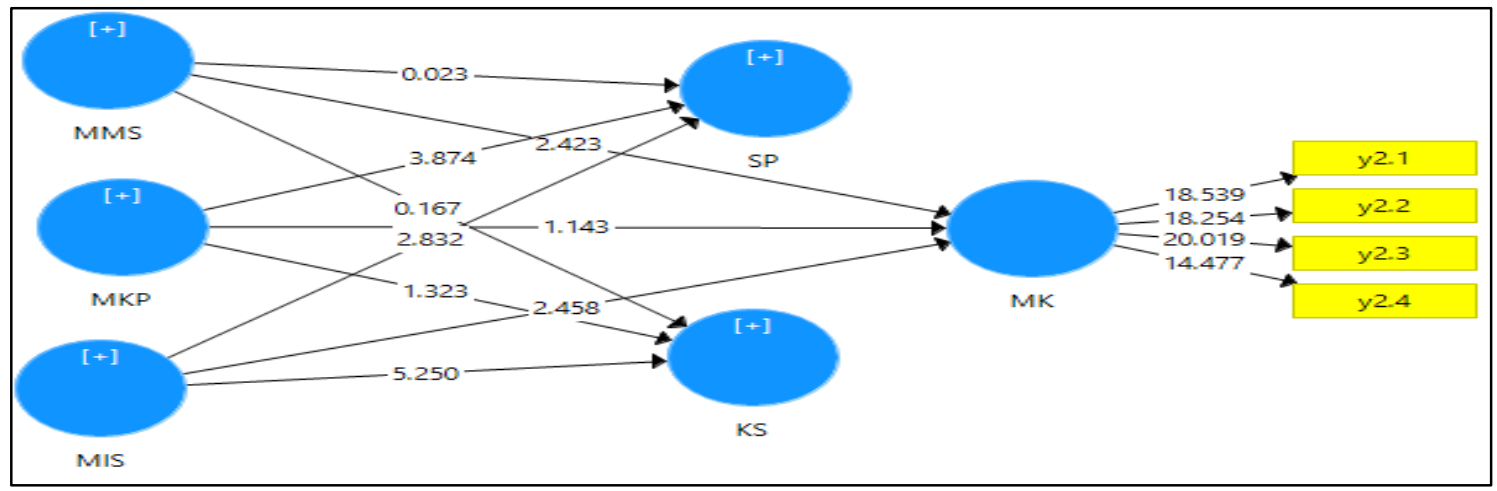

Gambar 1. Hasil bootstrapping model struktural

\section{Pembahasan}

Efikasi diri guru mampu menciptakan pembelajaran efektif, mempengaruhi motivasi dan capaian siswa melalui proses pembelajaran di kelas. Berdasarkan hasil analisa, disimpulkan bahwa kepemimpinan instruksional berpengaruh terhadap efikasi diri guru, temuan ini sesuai dengan penelitian Hoy \& Woolfolk 1993, Moran \& Hoy 2007, Calik dkk 2012, Fackler \& Malmberg 2016, dan Liu \& Hallinger 2018, hal ini dikarenakan kepala sekolah melakuakan perencanaan visi misi, mengelola kurikulum, dan menciptakan lingkungan sekolah yang mendukung guru untuk meningkatkan keprofesionalannya ${ }^{44}$, sehingga memberikan mastery experience, vicarious experiences, dan verbal persuasion kepada guru yang menjadi sumber efikasi diri ${ }^{45}$. Kesimpulan penelitian ini bertolak dengan penelitian Pearce 2017 dan Zheng dkk 2018 yang menyimpulkan kepemimpinan insruksional tidak berpengaruh pada efikasi diri guru ${ }^{46}$.

Berdasarkan hasil analisis dimensi dari kedua variabel, kepala sekolah dalam menciptakan iklim sekolah positif dan mengelola kurikulum pembelajaran berpengaruh terhadap strategi pembelajaran. Efikasi diri guru dalam hal strategi pembelajaran mengacu pada implementasi strategi dan penilaian yang berfariasi dengan berorientasi pada perkembangan siswa dan mencoba berbagai pendekatan agar menciptakan proses pembelajaran efektif ${ }^{47}$, kepala sekolah dalam memberikan dukungan pembelajaran, pengembangan keprofesionalan kepada guru, supervisi dan evaluasi serta memonitor perkembangan siswa akan membuat efikasi diri guru meningkat dan membuat guru lebih

${ }^{44}$ Hoy, Teacher Sense., hal. 355; Moran, The Differential., hal. 944; Calik dkk., Examination., hal. 2498; Fackler, Teacher Self., hal. 8; Liu, Principal., hal. 1; Hallinger dkk, 1983; Identifyng., hal. 84; Hallinger dan Wang, Assesing., hal. 25; Sedat Gumus dkk, "A Systematic Review Of Studies On Leadership Models In Educational Research From 1980 To 2014", Educational Management Administration \& Leadership, 1.24 (2016), hal. 1

${ }^{45}$ Moran dkk., Teacher Efficacy., hal. 202; Hoy, Teacher sense., hal 355; Bandura, Self-Efficacy., hal. 101; Moran, The Differential., hal. 944; Fackler, Teacher Self., hal.8

${ }^{46}$ Pierce, The effects., hal. 54; Zheng dkk., Exploring., hal. 11

${ }^{47}$ Moran dkk, Teacher., hal. 202; Ling dkk, Validity., hal. 29; Jaggernauth, Inverstigation., hal. 7 
kreatif dan inovatif dalam strategi pembelajaran ${ }^{48}$. Kesimpulan penelitian ini sesuai penelitian Bellibas \& Liu 2017 dan memperluas penelitian Ma \& Marion $2019^{49}$.

Kepala sekolah dalam mendefinisikan tujuan sekolah dan menciptakan iklim sekolah positif berpengaruh terhadap manajemen kelas. Efikasi diri guru dalam hal manajemen kelas mengacu pada pengelolaan kelas yang kondusif dan membuat siswa mengikuti peraturan kelas ${ }^{50}$. Kepala sekolah yang mendefinisikan tujuan sekolah berupa perencanaan yang matang dan kejelasan komunikasi yang tersampaikan kepada guru dan semua elemen sekolah, serta iklim sekolah yang mendukung untuk guru agar mampu mengembangkan profesionalnya membuat guru mengenali tujuan dan usaha spesifik untuk meraihnya dan meningkatkan efikasi dirinya dalam manajemen kelas ${ }^{51}$. Kesimpulan penelitian ini sesuai dengan penelitian Belibas \& Liu 2017 dan memperluas penelitian Ma \& Marion $2019^{52}$.

Kepala sekolah yang mendefinisikan tujuan sekolah, mengelola kurikulum pembelajaran, dan menciptakan iklim sekolah positif berpengaruh terhadap keterlibatan siswa. Efikasi diri guru dalam hal keterlibatan siswa mengacu pada kepercayaan dalam membangun hubungan dengan siswa dalam mengembangkan potensi serta memberi motivasi kepada siswa ${ }^{53}$. Kepala sekolah dalam merencanakan dan mengkomunikasikan tujuan sekolah, memberi bimbingan, feedback, kolaborasi supervisi pembelajaran, pengembangan keprofesionalan guru, serta dukungan pembelajaran akan membuat efikasi diri guru dalam hal keterlibatan siswa meningkat ${ }^{54}$, karena guru merasa dihargai, didukung, dan diberikan kesempatan untuk mengembangkan potensinya dengan budaya sekolah berorientasi pada pengembangan kualitas guru maupun siswa ${ }^{55}$, sehingga pada implementasinya dikelas, guru mampu mengembangkan potensi siswa ${ }^{56}$. Kesimpulan ini sesuai dengan Bellibas \& Liu 2017 dan memperluas penelitian Ma \& Marion $2019^{57}$.

${ }^{48}$ Hallinger dkk, Identifying., hal. 84; Hallinger \& Wang, Assesing., hal. 25; Gumus dkk., A Systematic., hal. 16; Ghaith, Relationship., hal. 456; Moran, The Differential., hal. 945

${ }^{49}$ Bellibas, Multilevel., hal. 49; Marion, Exploring., hal. 12

${ }^{50}$ Moran dkk., Teacher., hal. 233; Jaggernauth, An Investigation., hal. 7

${ }^{51}$ Hallinger dkk., Identifying., hal. 84; Robinson dkk., The Impact., hal. 659 ; Hoy, Teacher., hal. 365; Bandura, Self Efficacy., hal. 43-45; Hipp, Exploring., hal.17; Walker, Impact of., hal. 46; Horton, The Relationship., hal. 94

${ }^{52}$ Bellibas, Multilevel., hal. 49; Marion, Exploring., hal. 12

${ }^{53}$ Moran dkk., Teacher., hal. 202; Ling dkk, Validity., hal. 29; Jaggernauth, Investigation., hal. 7

${ }^{54}$ Horton, The Relationship., hal. 94; Duyar dkk., Multilevel., hal. 173; Bandura, Self-Efficacy., hal. 244; Marion, Exploring., hal. 12

${ }^{55}$ Bandura, Self-Efficacy., hal. 101; Moran dkk., Teacher., Hal. 202

${ }^{56}$ Jang dkk., Engaging., hal. 588

${ }^{57}$ Bellibas, Multilevel., hal. 49; Marion, Exploring., hal. 12 


\section{SIMPULAN}

Dimensi efikasi diri dalam hal strategi pembelajaran dipengaruhi oleh kepala sekolah dalam mengelola kurikulum dan menciptakan iklim sekolah, efikasi diri guru dalam manajemen kelas dipengaruhi oleh kepala sekolah yang mendefinisikan misi sekolah dan menciptakan iklim sekolah positif. Keterlibatan siswa yang menjadi dimensi efikasi diri guru dipengaruhi oleh tiga dimensi kepemipinan instruksional. Implementasi kepemimpinan instruksional kepala sekolah menjadi aspek yang mempengaruhi efikasi diri guru dengan perencanaan sekolah yang jelas, kurikulum yang terorganisir dengan baik, pemberian dukungan, bimbingan, dan kesempatan kepada guru untuk terus mengambangkan keprofesionalannya.

Berdasarkan hasil analisis, diperoleh $R^{2}$ dan effect size yang kecil namun signifikan, hal ini diharapkan bagi penelitian selanjutnya untuk mengkonfirmasi ulang dengan respondem yang lebih besar dan setting yang berbeda, karena analisis pada penelitian ini tidak memasukkan gambaran demografis dan variabel moderator seperti kepercayaan, kolaborasi guru dan kepuasan kerja dalam menganalisis data dikarenakan keterbatasan software dan keterbatasan peneliti.

\section{DAFTAR PUSTAKA}

Anwar, Ali. Statistika Untuk Penelitian Pendidikan Dan Aplikasinya Dengan Spss Dan Excel, Kediri: IAIT Press, 2009.

Armor, D., Oseguera, P. C., Cox, M., King, N., McDonnel, L., Pascal, A., Pauly, E., \& Zellman, G. Analysis Of The School Preferred Reading Program In Selected Los Angles Minority School, Santa Monica: RAND, 1976.

Bandura, A. "Self-Efficacy: Toward A Unifying Theory Of Behavioral Change". Psychological Review, (1977),84.2: 191-215. doi: 10.1037/0033-295X.84.2.191.

Bandura, A. "Self-Efficacy". dalam Encyclopedia Of Human Behavior Vol. 4, pp. 7181. Ed. V. S. Ramachaudran. New York: Academic Press, 1994.

Bandura, A. Self-Efficacy The Exercise Of Control, New York: W. H. Freeman and Company, 1997.

Bearman, P., \& McLaughlin, M. W. Federal Programs Supporting Educational Change, Vol. VII: Factor Affecting Implementation And Continuation, Santa Monica: RAND, 1997.

Bellibas, M. S., \& Liu, Y. "Multilevel Analysis Of The Relationship Between Principals' Perceived Practices Of Instructional Leadership And Teachers' Self-Efficacy 
Perceptions". Journal of Educational Administration, (2017), 55.1: 49-69. doi: 10.1108/JEA-12-2015-0116.

Bossert, S. T., Dwyer, D. C., Rowan, B., \& Lee, G. V. “The Instructional Management Role Of The Principal. Education Administration Quarterly, (1982), 18.3: 34-64. doi: 10.1177/0013161X82018003004.

Calik, T., Segin, F., Kavgaci, H., \& Kilinc, A. C. "Examination Of Relationships Between Instructional Leadership Of School Principals And Self-Efficacy Of Teachers And Collective Teacher Efficacy". Educational Sciences: Theory \& Practice, (2012), 12.4: 2498-2504. Diperoleh dari https://eric.ed.gov

Chin, W. W. "How To Write Up And Report PLS Analyses", dalam Handbook Of Partial Least Squares, pp. 655-690. eds. V. E. Vinzi, W. W. Chin, J. Henseler, \& H. Wang. Berlin: Springer, 2010.

Cohen, J. "A Power Primer". Psychological Bulletin, (1992), 112.1: 155-159. doi: 10.1037//0033-2909.112.1.155

Coladarci, T. “Teachers' Sense Of Efficacy And Commitment To Teaching”. The Journal of Experimental Education, (1992), 60.4: 323-337. doi:10.1080/00220973. 1992.9943869

Duyar, I., Gumus, S., \& Bellibas, M. S. "Multilevel Analysis Of Teacher Work Attitudes The Influence Of Principal Leadership And Teacher Collaboration”. International Journal of Educational Management, (2013), 27.7: 700-719. doi: 10.1108/IJEM09-2012-0107.

Edmonds, R. "Effective School For The Urban Poor". Educational Leadership, (1979). Diperoleh dari https://semanticscholar.org/

Fackler, S., \& Malmberg, L. E. “Teachers' Self-Efficacy In 14 OECD Countries: Teacher, Student Group, School And Leadership Effects". Teaching and Teacher Education, (2016), 56: 185-195. doi: 10.1016/j.tate.2016.03.002.

Fahimi, M. "Cluster Sample”. Dalam Encyclopedia Of Survey Research Methods, pp.9899. Ed. P. J. Lavrakas. Thousand Oaks, CA: Sage, 2008.

Fornell, C., \& Larcker, D. F. "Evaluating Structural Equation Models With Unobservable Variables And Measurement Error”. Journal of Marketing Research, (1981), 18: 39-50. doi: 10.2307/3151312.

George, B., \& Pandey, S. K. "We Know The Yin But Where Is The Yang? Toward A Balanced Approach On Common Source Bias In Public Administration Scholarship". Review of Public Personnel Administration, (2017), 37.2: 245-270. doi: 10.1177/0734371X17698189. 
Ghaith, G \& Yaghi, H. "Relationships Among Experience, Teacher Efficacy, And Attitudes Toward The Implementation Of Instructional Innovation". Teaching and Teacher Education, (1997), 13.4: 451-458. doi: 10.1016/S0742-051X(96)00045-5

Gumus, S., Bellibas, M. S., Esen, M., Gumus, E. "A Systematic Review Of Studies On Leadership Models In Educational Research From 1980 To 2014. Educational Management Administration \& Leadership, (2016), 1.24: 25-48. doi: 10.1177/ 1741143216659296.

Hair, J.F., Hult, G. M. T., Ringle, C. M., \& Sarstedt, K. A primer on Partial Least Squares Structural Equation Modeling (PLS-SEM). Thousand Oaks, CA: Sage Publication, 2017.

Hallinger, P. "The Evolving Role Of American Principals: From Managerial To Instructional To Transformational Leaders". Journal of Educational Administration, (1992), 30.3: 35-48. doi: 10.1108/09578239210014306.

.,"Exploring The Principals Contribution To School Effectiveness: 1980-1995". School Effectiveness and School Improvement, (1998), 9.2: 157-191. doi: 10.1080/0924345980090203.

Hallinger, P., Lee, M. "Exploring Principal Capacity To Lead Reform Of Teaching And Learning Quality In Thailand". International Journal of Educational Development, (2013), 33.4: 305-315. doi: 10.1016/j.ijedudev.2012.03.002.

Hallinger, P., Murphy, J., Weil, M., Mesa, R. P., Mitman, A. "Identifying The Specific Practices, Behaviors For Principals. NASSP Bulletin, (1983), 67.463: 83-91. doi: $10.1177 / 019263658306746314$.

Hallinger, P., \& Wang, W. C. Assessing Instructional Leadership With The Principal Instructional Management Rating Scale. New York: Springer International Publishing Switzerland, 2015.

Henseler, J., Ringle, C. M., \& Sarstedt, M. “A New Criterion For Assessing Discriminant Validity In Variance-Based Structural Equation Modeling". Journal of Academy of Marketing Science, (2015), 43: 115-135. doi: 10.1007/s11747-014-0403-8.

Hipp, K., A. Exploring Relationships Between Principals' Leadership Behaviors And Teachers' Sense Of Efficacy [Makalah]. American Educational Research Association. New York: Ball State University, 1996. https://eric.ed.gov

Horton, T. The Relationship Between Teachers' Sense Of Efficacy And Perceptions Of Principal Instructional Leadership Behaviors In High Poverty Schools, Disertasi Doktoral. (2013). Diperoleh dari https://rc.library.uta.edu/ 
Hoy, W. K., \& Woolfolk, A. E. "Teachers' Sense Of Efficacy And The Organizational Health Of Schools". The Elementary School Journal, (1993), 93.4: 355-372. doi: $\underline{10.1086 / 461729 .}$.

Jaggernauth, S., \& Charles, M. J. “An Investigation Of The Influence Of Teacher Variables On Pre-Training Efficacy Beliefs". Caribbean Teaching Scholar, (2015), 5.1. Diperoleh dari https://www.researchgate.net

Jang, H., Reeve, J., \& Deci, E. L. "Engaging Students In Learning Activities: It Is Not Autonomy Support Or Structure But Autonomy Support And Structure”. American Psychological Association, (2010),102.3: 588. doi: 10.1037/a0019682

Kim, K. R., \& Seo, E. H. “The Relationship Between Teacher Efficacy And Students' Academic Achievement: A Meta-Analysis”. Social Behavior And Personality, (2018), 46.4: 529-540. doi: 10.2224/sbp.6554

Kish, L. Statistical Design For Research. Hoboken, NJ: John Wiley, 2004.

Ling, T. P., Pihie, Z. A. L., Asimirin, S., \& Fooi, S. F. "The Validity And Reliability Of Teacher Efficacy Revisited In Malaysia Secondary Schools”. Journal of Studies in Education, (2015), 5.1: 27-35. doi: 10.5296/jse.v5i1.6802.

Liu, S., \& Hallinger, P. "Principal Instructional Leadership, Teacher Self-Efficacy, And Teacher Professional Learning In China: Testing A Mediated-Effects Model”. Educational Administration Quarterly, (2018), 54.4: 501-528. doi: 10.1177/ $0013161 X 18769048$.

Ma, X., \& Marion, R. "Exploring How Instructional Leadership Affects Teacher Efficacy: A Multilevel Analysis". Educational Management Administration \& Leadership, (2019), 1-20. doi: 10.1177/1741143219888742.

McCoach, D. B., \& Adelson, J. L. "Dealing With Dependence: Understanding The Effects Of Clustered Data”. Gifted Child Quarterly, (2010), 54.2: 152-155. doi: 10.1177/0016986210363076.

Moran, M.T., \& Hoy, A. W. "Teacher Efficacy: Capturing An Elusive Construct. Teaching and Teacher Education, (2001), 17.7: 783-805. doi: 10.1016/S0742051X(01) 00036-1.

,"The Differential Antecedents Of Self-Efficacy Beliefs Of Novice And Experienced". Teaching and Teacher Education, (2007), 23.6: 944-956. doi: 10.1016/j.tate.2006.05.003.

Moran, M. T., Hoy, A. W., \& Hoy, W. K. "Teacher Efficacy: Its Meaning And Measure”. Review Of Educational Research, (1998), 68.2: 202-248. doi: 10.3102/0034654306 8002202. 
Pearce, M. L. “The Effects Of Instructional Leadership On Teacher Efficacy”, Disertasi Doktoral, (2017). Diperoleh dari https://www.semanticscholar.org/

Podsakoff, P. M., MacKenzie, S. B., Lee, J.-Y., \& Podsakoff, N. P. "Common Method Biases In Behavioral Research: A Critical Review Of The Literature And Recommended Remedies”. Journal of Applied Psychology, (2003), 88.5: 879-903. doi: 10.1037/0021-9010.88.5.879.

Robinson, V. M. J., Lloyd, C. A., Rowe, K. J. "The Impact Of Leadership On Student Outcomes: An Analysis Of The Differential Effects Of Leadership Types". Educational Administration Quarterly, (2008), 44.5: 635-674. doi: 10.1177/ $\underline{0013161 X 08321509 .}$

Shackman, G. Design effect [Makalah Seminar]. American Statistical Association: Albani, New York, (2001, 24 Maret). http://faculty.smu.edu/slstokes

Shatzer, R. H., Caldarella, P., Hallam, P. R., \& Brown, B. L. "Comparing The Effects Of Instructional And Transformational Leadership On Student Achievement: Implications For Practice". Educational Managemen Administration \& Leadership, (2014), 42.4: 445-459. doi: 10.1177/1741143213502192.

Walker, J., \& Slear, S. "The Impact Of Principal Leadership Behaviors On The Efficacy Of New And Experienced Middle School Teachers”. NASSP Bulletin, (2011), 95.1: 46-64. doi: 10.1177/0192636511406530.

Weber, G. "Inner-City Children Can Be Taught To Read: Four Successful School". Makalah. CBE Occasional, 1971. Diperoleh dari https://files.eric.ed.gov

Zee, M., \& Koomen, H. M. Y. "Teacher Self-Efficacy And Its Effects On Classroom Processes, Student Academic Adjustment, And Teacher Well-Being: A Synthesis Of 40 Years Of Research". Review of Educational Research, (2016), 20.10: 1-35. doi: 10.3102/003465431562680.

Zheng, X., Yin, H., \& Li, Z. "Exploring The Relationships Among Instructional Leadership, Professional Learning Communities And Teacher Self-Efficacy In China”. Educational Management Administration \& Leadership, (2018), 47.6: 120. doi: $10.1177 / 1741143218764176$. 